Article

\title{
Brazing of Mo to Glidcop Dispersion Strengthened Copper for Accelerating Structures
}

\author{
Valentina Casalegno ${ }^{1, *}$, Sergio Perero ${ }^{1}{ }^{\circledR}$, Monica Ferraris ${ }^{1}$, Mauro Taborelli ${ }^{2}$, \\ Gonzalo Arnau Izquierdo ${ }^{2}$, Stefano Sgobba ${ }^{2}$ and Milena Salvo ${ }^{1}$ (D) \\ 1 Applied Science and Technology Department, Institute of Materials Physics and Engineering, \\ Politecnico di Torino, I-10129 Torino, Italy; sergio.perero@polito.it (S.P.); \\ monica.ferraris@polito.it (M.F.); milena.salvo@polito.it (M.S.) \\ 2 CERN European Organization of Nuclear Research, CH-1211 Geneva, Switzerland; \\ Mauro.Taborelli@cern.ch (M.T.); Gonzalo.Arnauizquierdo@cern.ch (G.A.I.); Stefano.Sgobba@cern.ch (S.S.) \\ * Correspondence: valentina.casalegno@polito.it; Fax: +39-011-564-4699
}

Received: 18 July 2018; Accepted: 27 August 2018; Published: 7 September 2018

\begin{abstract}
Alumina dispersion-strengthened copper, Glidcop, is used widely in high-heat-load ultra-high-vacuum components for synchrotron light sources (absorbers), accelerator components (beam intercepting devices), and in nuclear power plants. Glidcop has similar thermal and electrical properties to oxygen free electrical (OFE) copper, but has superior mechanical properties, thus making it a feasible structural material; its yield and ultimate tensile strength are equivalent to those of mild-carbon steel. The purpose of this work has been to develop a brazing technique to join Glidcop to Mo, using a commercial Cu-based alloy. The effects of the excessive diffusion of the braze along the grain boundaries on the interfacial chemistry and joint microstructure, as well as on the mechanical performance of the brazed joints, has been investigated. In order to prevent the diffusion of the braze into the Glidcop alloy, a copper barrier layer has been deposited on Glidcop by means of RF-sputtering.
\end{abstract}

Keywords: brazing; alumina dispersion-strengthened copper; mechanical testing

\section{Introduction}

Glidcop is a family of dispersion strengthened copper alloys, made of a pure copper matrix strengthened by a uniform dispersion of alumina particles. These particles, which are stable at high temperatures and above the melting point of the matrix, have the aim of preventing the softening and recrystallization of the copper when treated at high temperatures [1]. Glidcop exhibits an improved mechanical resistance, especially at high temperatures, with respect to copper, and at the same time it maintains an excellent thermal conductivity. For these reasons, it has been considered, from the very beginning, as a suitable support material for the collimator jaws of modern particle accelerators [2], with the idea that the Glidcop block could be efficiently cooled and would work as a heat sink for the jaw itself. In this sense, it is still the material of choice for the next generation supports of the collimators [3] that have to be installed on the Large Hadron Collider (LHC) during the long shutdown 2. The jaws close to the Glidcop holder are made of a sequence of materials with an increasing atomic number, so that the extremely high energetic proton beam halo is gradually dispersed and finally absorbed. As a consequence, refractory materials, such as tungsten, molybdenum, inermet or similar, are used. In this sense, an effective joint between a highly conducting material and a high $\mathrm{Z}$ material could be of interest. The present work focuses on the development of a brazing process for pure Mo and a Glidcop alloy. The authors have already investigated the joining of a CuZr alloy (UNS C15000, 80\% cold worked) and Mo in the framework of the Compact Linear Collider (CLIC) project [4]; the accelerating structure is traditionally made of brazed oxygen free electrical (OFE) copper parts, 
but CuZr and Glidcop could represent improved alternatives for the conducting regions that suffer from to mechanical fatigue. Moreover, the study of the joining of Glidcop can be considered relevant, not only for the particle accelerator components, but also for other application fields, such as resistance welding electrodes, incandescent light bulb leads, hybrid circuit packages and other high temperature applications, such as X-ray tube components or heat exchanger components $[5,6]$.

Several methods have been proposed to join Glidcop to such metals as $\mathrm{Cu}$ or stainless steel [7-10]. An assembly of Glidcop cooling pipes, coated with a sacrificial armor in pure $\mathrm{W}$ or $\mathrm{W}$ alloys has been obtained for the diverter component using TiCuAg alloy as the joining material [6], but to the best of the authors' knowledge, no joint between Glidcop and Mo has yet been manufactured or characterized. Of all the different joining technologies, the brazing process is known to play the most important role in the joining of Glidcop. Moreover, fusion welding, including electron beam welding, is not suitable for the joining process because the remelting of the copper matrix leads to an agglomeration of the alumina particles and recrystallization of the matrix in the welding area, thus creating a brittle welded zone [11].

The brazing of Glidcop is usually carried out with the brazing filler metals that are commonly used to join plain copper (i.e., gold- and silver-based braze alloys). The brazing of copper generally leads to a grain coarsening, due to the grain growth that occurs during the brazing process. Glidcop does not suffer from this problem, because of its fine structure and reduced recrystallization at the brazing temperatures.

The main problem related to the brazing of Glidcop is the excessive diffusion of the silver-based filler along the grain boundaries of Glidcop. The electroplating of Glidcop with copper or nickel prior to brazing is used as a common method to prevent and solve this issue [10]. Copper plating is usually carried out in a copper cyanide solution; the cyanide-copper bath has the aim of facilitating the quality of the braze joints by preventing diffusion of the braze alloy into the Glidcop base material. On the other hand, the $\mathrm{Cu}$-plating process introduces additional steps in the manufacturing process, since additional control stages are needed to ensure blister-free plating. Nickel plating is obtained through more complicated processes, which are based on a Watts bath or electroplating.

The purpose of this work has been to develop a brazing technique to join Glidcop to Mo using a commercial silver-free $\mathrm{Cu}$-based alloy. In order to prevent the diffusion of the braze into the Glidcop, a copper barrier layer has been deposited on the Glidcop by means of RF-sputtering, an environmentally friendly coating technique, which does not require the use of any hazardous chemicals.

\section{Materials and Methods}

Glidcop is a metal matrix composite made up of oxygen free copper and aluminum oxide; it consists of more than 99\% copper. The Glidcop Grade used in this work is Glidcop AL-25, in which the aluminum oxide content is $0.5 \mathrm{wt} . \%$; the commercial name is UNS-C15725, and the $\mathrm{Al}_{2} \mathrm{O}_{3}$ submicroscopic dispersed particle size ranges from 3 to $12 \mathrm{~nm}$; it was supplied by Höganäs $\mathrm{AB}$ (Höganäs, Sweden), while the Mo ( $99.97 \%$ purity) was supplied by Plansee (Gemeinde Reutte, Austria).

The joining process between Glidcop and Mo was performed using a silver-free commercial metal braze (Gemco), which does not contain elements such as $\mathrm{Ti}$, $\mathrm{Si}$, etc. that could lead to the formation of brittle intermetallics with $\mathrm{Cu}$. The braze was supplied by Wesgo Metals, and it is composed of $87.75 \mathrm{wt} . \% \mathrm{Cu}, 12 \mathrm{wt} . \% \mathrm{Ge}$ and $0.25 \mathrm{wt} . \% \mathrm{Ni}$; it has a liquidus temperature at $975{ }^{\circ} \mathrm{C}$ and a solidus temperature at $880^{\circ} \mathrm{C}$. The braze foil thickness is about $60 \mu \mathrm{m}$.

The wettability of the brazing alloy on the Glidcop alloy was measured by means of a hot stage microscope (model AII, Leitz GmbH, Wetzlar, Germany), up to $1000{ }^{\circ} \mathrm{C}$ under flowing Ar, at a heating rate of $20^{\circ} \mathrm{C} \cdot \mathrm{min}^{-1}$, equipped with a Leica DBP camera (Ernst Leitz GMBH, Wetzlar, Germany).

The adherends were cut using a diamond-grinding disc, and this was followed by grinding with 2500 grit $\mathrm{SiC}$ paper. The final polishing was performed using a $3 \mu \mathrm{m}$ diamond paste. The samples were then cleaned in an ultrasonic bath with acetone for $5 \mathrm{~min}$ to remove surface impurities. A Cu coating was deposited on the Glidcop plates for a certain set of samples, by means of Radio Frequency 
magnetron sputtering, before the brazing process. A copper target (99.99\% purity), supplied by Franco Corradi (Rho (MI), Italy), was used.

The sputtering deposition parameters were varied in order to optimize the homogeneity of the coating. A pure Ar (99.996\% purity) atmosphere was used to avoid oxidization of the sputtered layer during deposition.

The cathode-substrate distance was maintained fixed at $14 \mathrm{~cm}$. The pre-deposition pressure reached $7.0 \times 10^{-5} \mathrm{~Pa}$, while the Ar pressure was $55 \times 10^{-1}$ Pa during deposition.

A power of $250 \mathrm{~W}$ was applied in RF (radio frequency), to a 6 inch diameter target. This value was selected, after some preliminary depositions, in order to balance the deposition rate, which needed to be as high as possible, and the thin film morphology. Low power can lead to voids and defects in the layer, while high power can create other unwanted structures, such as columns and recrystallization. The film thickness was controlled while varying the deposition time. Different time periods (from $20 \mathrm{~min}$ to $7 \mathrm{~h}$ ) were considered to obtain $\mathrm{Cu}$ coatings of various thickness (from $1 \mu \mathrm{m}$ to $18 \mu \mathrm{m}$ ). The thickness measurements were performed by means of a surface profiler (Tenkor P11, KLA-Tenkor, Milpitas, CA, USA). The homogeneity area of the deposition surface was around $100 \mathrm{~mm}^{2}$.

The produced joints were sandwich-like Mo/Gemco/Glidcop. The metallic parts that had to be joined and the brazing alloy foil were sectioned into $5 \mathrm{~mm} \times 10 \mathrm{~mm}$ pieces, to obtain a joining surface of $50 \mathrm{~mm}^{2}$. One foil or three foils of the Gemco brazing alloy were used. The brazing was performed in a horizontal tube furnace (BICASA, Camera SUPERTHAL, Bernareggio (MB), Italy) under flowing Ar; the brazing temperature was chosen slightly above the filler metal liquidus temperature $\left(980^{\circ} \mathrm{C}\right)$, and the heating rate adopted to reach the brazing temperature was $1000{ }^{\circ} \mathrm{C} \cdot \mathrm{h}^{-1}$. The dwelling time was varied from $1 \mathrm{~min}$ to $30 \mathrm{~min}$; the specimens were then allowed to cool to room temperature in the furnace (cooling rate of $5{ }^{\circ} \mathrm{C} \mathrm{min}-1$ ). The influence of a tungsten weight $(100 \mathrm{~g}$, corresponding to $0.02 \mathrm{MPa}$ nominal pressure) on the top of the Mo/Glidcop sandwich structure was also investigated. This applied load is about ten times the specimens' own mass.

The microstructure of the joined samples was investigated by means of optical and electron microscopy (SEM, Philips 525 M, FEI_thermo Fisher Scientific, Hillsboro, OR, USA, accelerating voltage $=15-30 \mathrm{kV}$ ) coupled with energy dispersive spectroscopy for the compositional analysis (EDS SW9100 EDAX and Oxford Isis 300, EDAX-AMETEK Materials Analysis Division, Meerbusch, Germany).

The apparent shear strength of the joints was measured with a single-lap test under compression, adapted from ASTM D905-08 standard [12], specimen size: $5 \times 10 \times 3 \mathrm{~mm}$, seen in Figure 1B, and according the ASTM B898-11 standard [13] (Glidcop size of $25 \times 15 \times 10 \mathrm{~mm}$ and Mo size of $4 \times 15 \times 4 \mathrm{~mm}$ ), seen in Figure 1A, at room temperature (universal testing machine SINTEC D/10, MTS Systems, Eden Prairie, Minnesota, USA). The shear strength was determined as the ratio of the load measured at the fracture and the joined area. The compressive force was applied at a speed of $0.5 \mathrm{~mm} \cdot \mathrm{s}^{-1}$. The fracture surfaces were examined to determine the fracture propagation. Rockwell B hardness measurements were performed on the Glidcop surface, before and after the brazing process, using an Officine Galileo hardness tester (Durometro Galileo A200, Rockwell, Officine Galileo, Capalle (FI), Italy). 


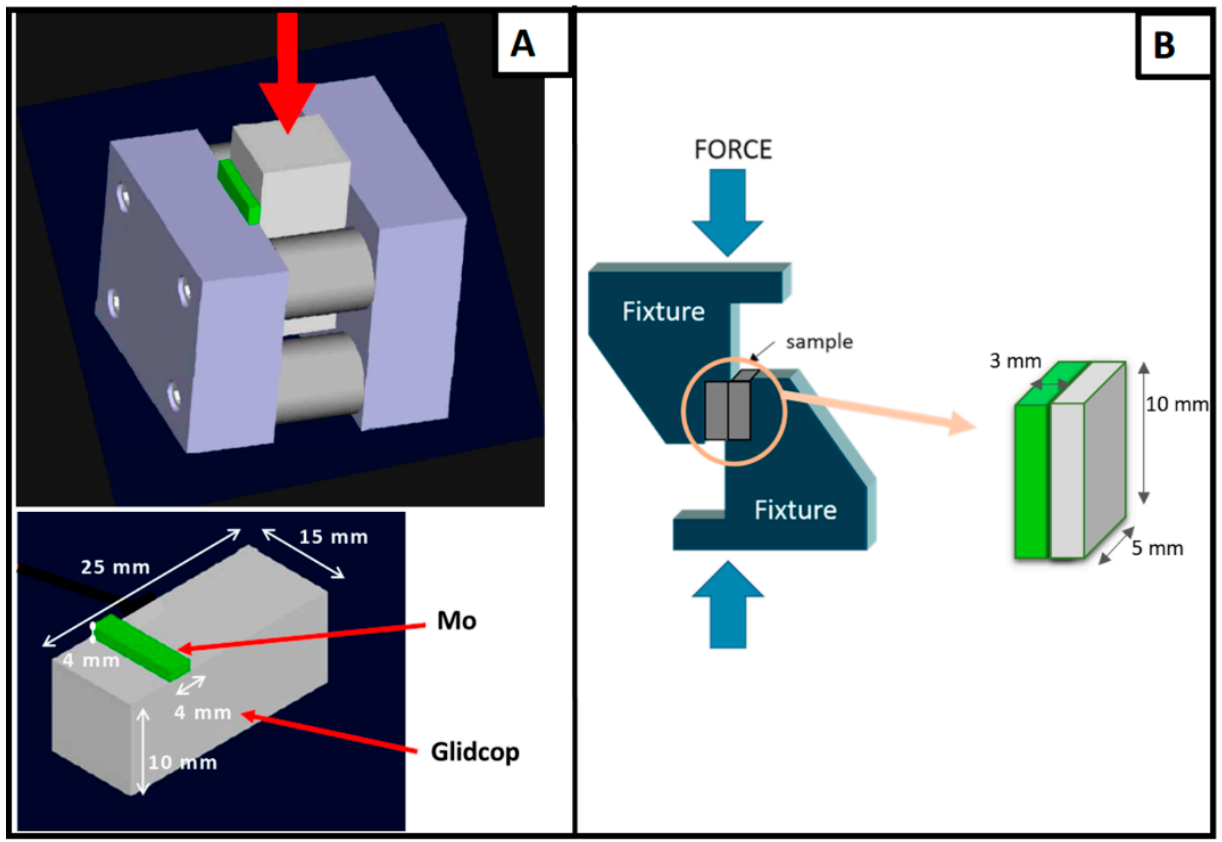

Figure 1. Configuration for measuring the apparent shear strength of Mo/Glidcop joined samples: (A) ASTM B898-11 standard (Glidcop size of $25 \times 15 \times 10 \mathrm{~mm}$ and Mo size $4 \times 15 \times 4 \mathrm{~mm}$ ) and (B) single-lap test, adapted from ASTM D905-08 (adherends size: $5 \times 10 \times 3 \mathrm{~mm}$ ).

\section{Results and Discussion}

The wettability of the brazing alloy was only measured on the Glidcop substrate, in order to demonstrate the compatibility and spreading of the braze on Glidcop; the braze wettability on Mo had already been presented and discussed elsewhere [4]; moreover, the wetting of the Cu-Mo system is a well-known and broadly studied topic [14]. The wettability test showed that the molten alloy starts spreading at $920^{\circ} \mathrm{C}$ and at $980{ }^{\circ} \mathrm{C}$ the contact angle between the molten Gemco and Glidcop reaches its lowest value, as seen in Figure 2. An equilibrium configuration is reached almost immediately, that is, after one min at $980^{\circ} \mathrm{C}$; after $15 \mathrm{~min}$ of contact, no variation in the spreading behavior was observed.

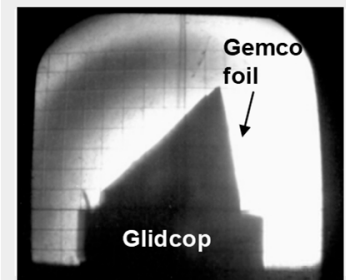

T room

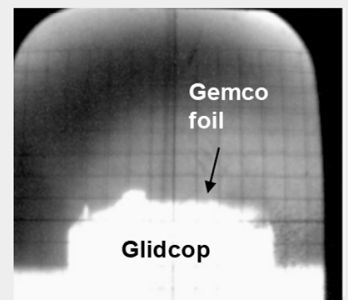

$\mathrm{T}=950^{\circ} \mathrm{C}$

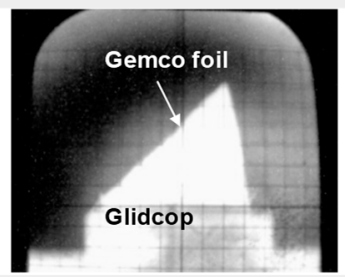

$\mathrm{T}=850^{\circ} \mathrm{C}$

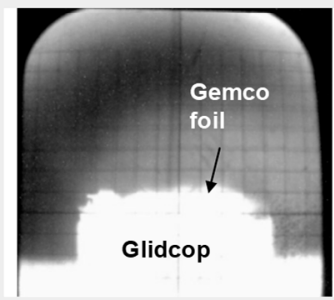

$\mathrm{T}=960^{\circ} \mathrm{C}$

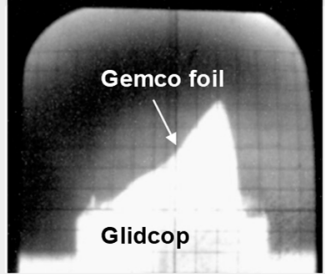

$\mathrm{T}=900^{\circ} \mathrm{C}$

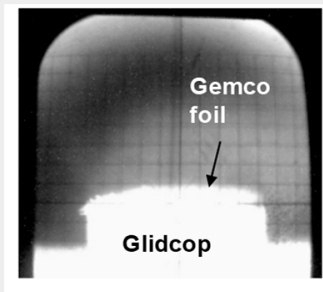

$\mathrm{T}=980^{\circ} \mathrm{C}$

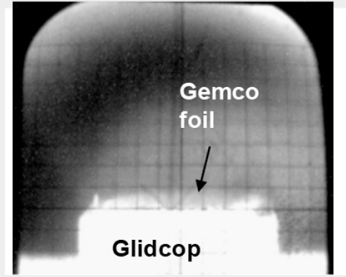

$\mathrm{T}=920^{\circ} \mathrm{C}$

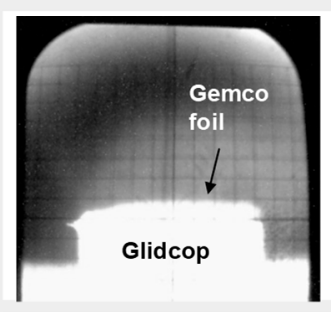

$\mathrm{T}=980^{\circ} \mathrm{C}$ (after $\left.15 \mathrm{~min}\right)$

Figure 2. Hot stage microscope images of a Gemco braze foil on Glidcop substrate; the best spreadability was reached at $980^{\circ} \mathrm{C}$ (under flowing Ar, heating rate $20^{\circ} \mathrm{C} \cdot \mathrm{min}^{-1}$ ). 
As far as the brazing process is concerned, a preliminary study was carried out to optimize the thickness of the joint and its microstructure. The joint gap was controlled by the thickness of the brazing filler foil; a reduction in the joint thickness can be helpful to obtain a joint with good electrical properties [4]. The brazing treatment was performed at $980^{\circ} \mathrm{C}$, that is, at a temperature slightly above the liquidus of the filler alloy, in order to reach the best spreadability and wettability of the braze and to avoid the recovery and the softening of the copper alloy $[8,9]$.

Figure 3 shows a SEM cross-section of an Mo/Gemco/Glidcop joint obtained using one braze foil (at $980{ }^{\circ} \mathrm{C}$ for $5 \mathrm{~min}$, under flowing Ar and applying $0.02 \mathrm{MPa}$ ).

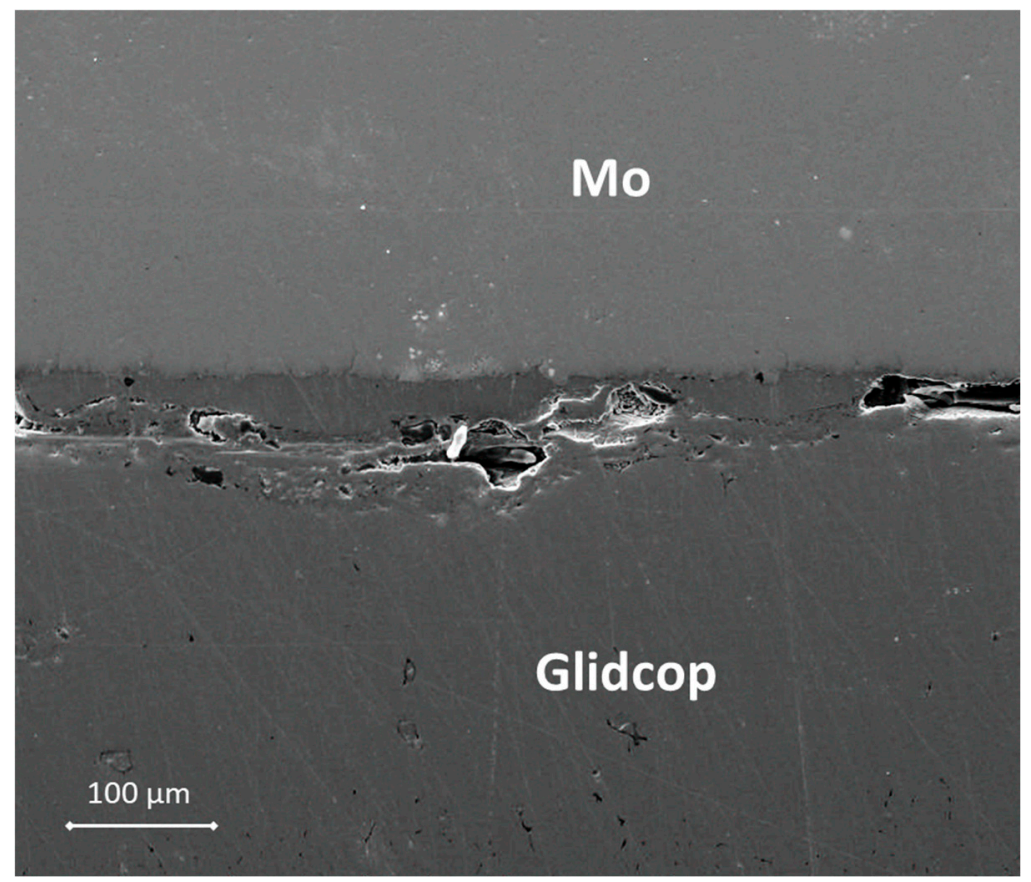

Figure 3. SEM micrograph of the cross-section of a Mo/Gemco/Glidcop joint manufactured by using one Gemco braze foil at $980{ }^{\circ} \mathrm{C}, 5 \mathrm{~min}$, under flowing Ar and applying $0.02 \mathrm{MPa}$.

The thickness of the braze metal, after the thermal treatment in the samples joined with one brazing alloy foil, was about $40 \mu \mathrm{m}$. Because of the high wettability of the brazing alloy on the substrates, the braze can flow out of the joint gap, thus justifying the reduction in braze thickness. Several voids in the filler metal layer were visible and the interface was not continuous. On the other hand, there is little evidence of significant defects, such as micro-voids, in the joints manufactured using three Gemco braze foils, shown in Figure 4, due to braze solidification shrinkage, and both Mo and Glidcop exhibit a good metallurgical continuity in the interfacial region. Moreover, a comparison between two Mo/Glidcop joints obtained with three Gemco foils at $980^{\circ} \mathrm{C}, 5 \mathrm{~min}$, but with and without a superimposed load (100 g, corresponding to $0.02 \mathrm{MPa}$ nominal pressure), was carried out. When the pressure was not applied to the assembly, a higher number of voids developed, due to the shrinkage of the liquid braze (pictures not reported here); then, the introduction of an external load during the brazing process was able to reduce these voids. From a qualitative observation of the cross-section of the samples, the surface corresponding to voids is reduced by $80 \%$. Further investigations were addressed to optimize the dwelling time; all the different experimental parameters are summarized in Table 1. 


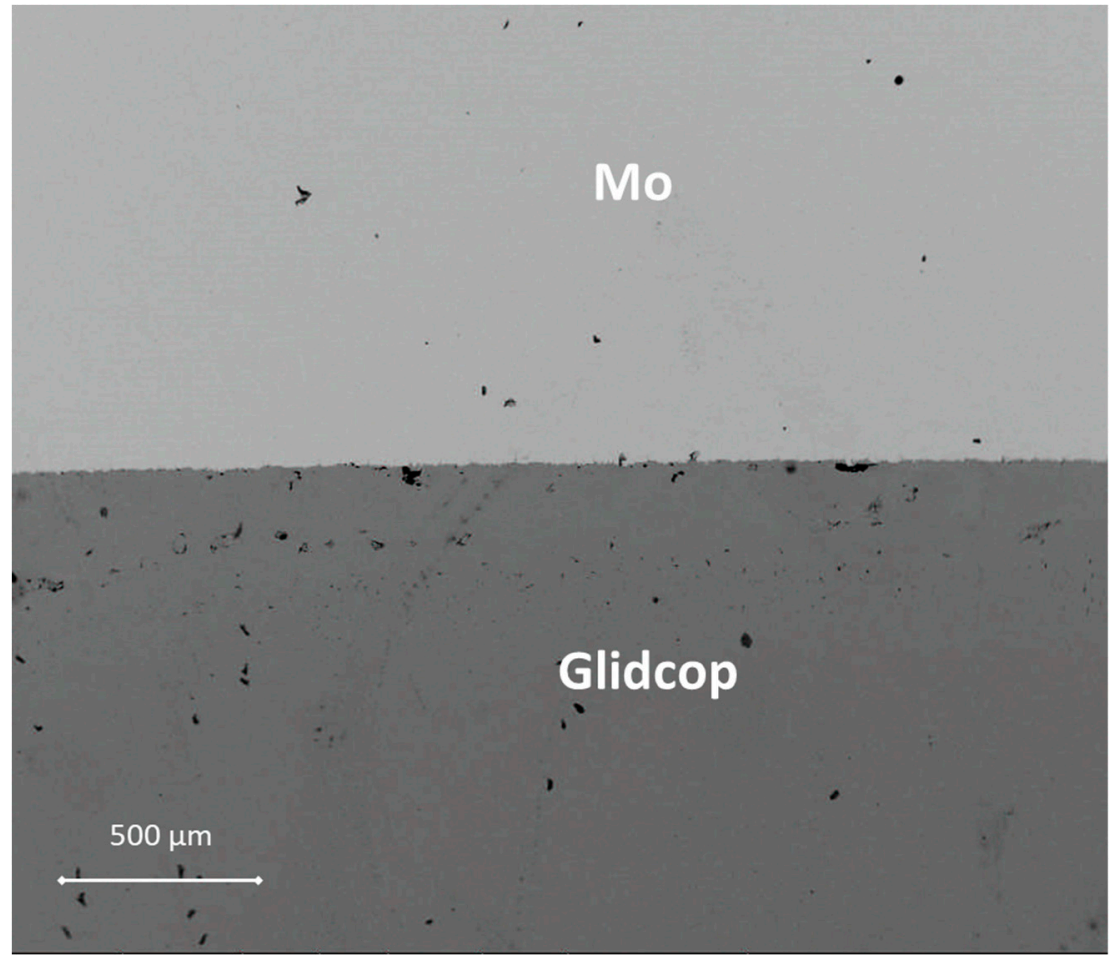

Figure 4. SEM micrograph of the cross-section of a Mo/Gemco/Glidcop joint manufactured by using three Gemco braze foils at $980{ }^{\circ} \mathrm{C}, 5 \mathrm{~min}$, under flowing Ar and applying $0.02 \mathrm{MPa}$.

Table 1. Brazing parameters for several sets of samples; joining temperature fixed at $980{ }^{\circ} \mathrm{C}$, heating rate $1000{ }^{\circ} \mathrm{C} / \mathrm{h}$, Ar atmosphere (100 g superimposed weight corresponds to $0.02 \mathrm{MPa}$ nominal pressure).

\begin{tabular}{cccccccccc}
\hline & & Sample 1 & Sample 2 & Sample 3 & Sample 4 & Sample 5 & Sample 6 & Sample 7 & Sample 8 \\
\hline \multirow{2}{*}{ Set up } & $\begin{array}{c}\text { Number of Brazing Foils } \\
\text { Superimposed Weight }(100 \mathrm{~g})\end{array}$ & $\begin{array}{c}\text { yes } \\
\text { Process parameters }\end{array}$ & $\begin{array}{c}3 \\
\text { Des }\end{array}$ & $\begin{array}{c}3 \\
\text { no }\end{array}$ & $\begin{array}{c}1 \\
\text { yes }\end{array}$ & $\begin{array}{c}1 \\
\text { no }\end{array}$ & $\begin{array}{c}3 \\
\text { yes }\end{array}$ & $\begin{array}{c}3 \\
\text { yes }\end{array}$ & $\begin{array}{c}3 \\
\text { yes }\end{array}$ \\
\hline
\end{tabular}

In order to study the distribution of the elements across the joint region, EDS analyses were performed on the Mo/Gemco/Glidcop samples brazed using three braze foils (best morphological result, according to the microstructure shown in Figure 4) at $980^{\circ} \mathrm{C}$ for 1, 5, 10, 15, 30 min and applying $0.02 \mathrm{MPa}$ (pictures not reported here). Germanium diffused extensively from the braze to the Glidcop substrate in all the samples. The Ni content could not be determined because its concentration was too low ( $0.25 \mathrm{wt} . \%$ of $\mathrm{Ni}$ in the brazing alloy).

Further investigations, by means of SEM, allowed an excessive diffusion of the braze to be detected along the grain boundaries of the Glidcop alloy, as it is possible to observe in the micrographs reported in Figure 5 for samples brazed at $980{ }^{\circ} \mathrm{C}$ for both 5 and $30 \mathrm{~min}$ using three Gemco alloy foils and applying $0.02 \mathrm{MPa}$. 

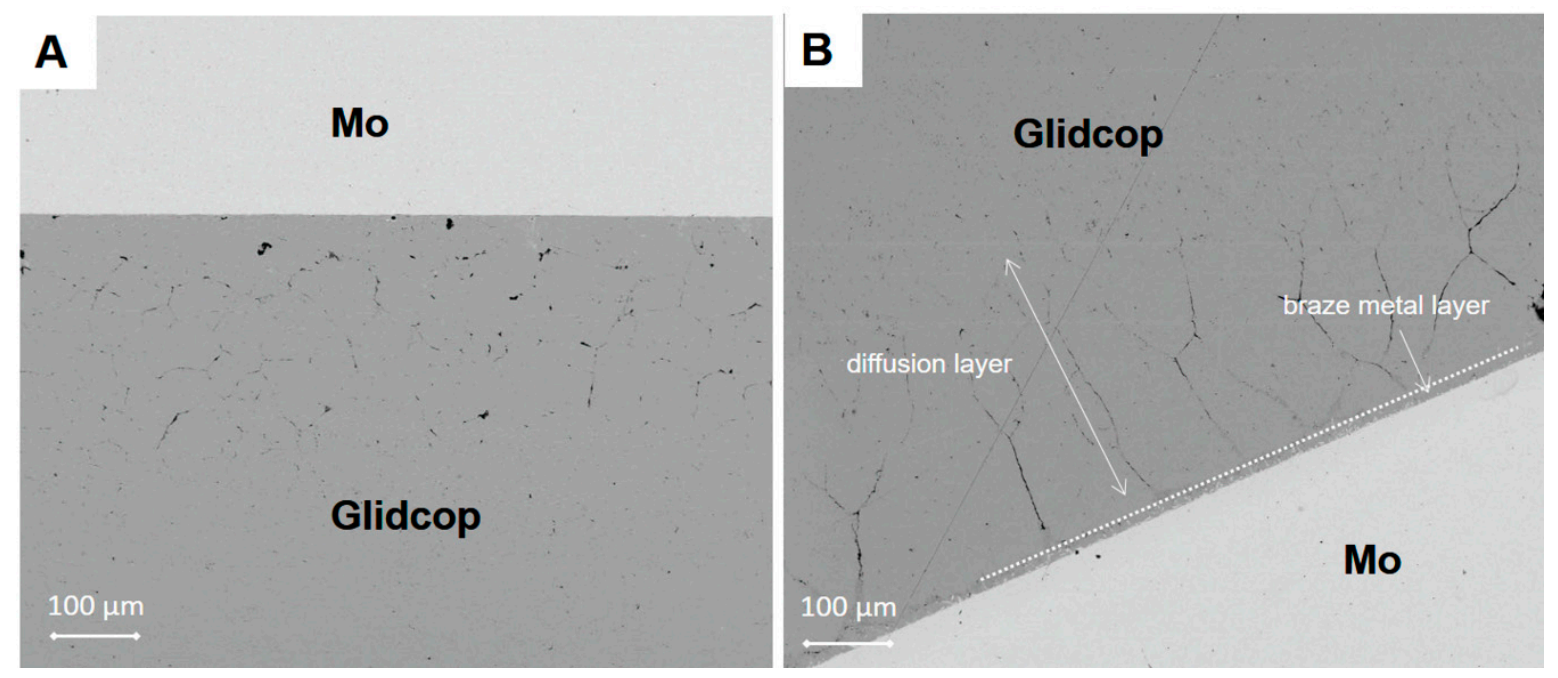

Figure 5. SEM micrographs of the cross-section of a Glidcop/Mo interface obtained by means of brazing (three Gemco braze foils) at $980{ }^{\circ} \mathrm{C}$ for $5 \mathrm{~min}$ (A) and for $30 \mathrm{~min}$ (B) under flowing Ar and applying $0.02 \mathrm{MPa}$.

This result is consistent with the common diffusion theory and literature references. Several studies [15] have reported that, during the brazing of Glidcop with gold or silver alloys (mainly Au-Cu or Ag-Cu based alloys), there is a tendency of the gold or silver to diffuse into the Glidcop, depending on the duration of the brazing cycle. To the best of the authors' knowledge, no studies on Ge and Ni diffusion in DS-copper alloys are available in literature.

The brazed area can be divided into the braze metal layer and the diffusion layer, in which the liquid metal migrates along the Glidcop grain boundaries, as indicated in Figure 5. In the BSE-SEM images shown in Figure 5, the braze was found to migrate along the Glidcop grain boundaries for several hundreds of microns, thus determining the formation of a significant porosity in the Glidcop alloy; there is evidence that the number of voids at the grain boundaries increases slightly and the voids grow in size (qualitative observation, void ratio/size not investigated) on the basis of the brazing process dwelling time (the effect of the temperature has not been studied here). This phenomenon can be explained by considering the coalescence of the pre-existing voids at the grain boundary or by the depletion of elements (i.e., Ge) from the brazing alloy that penetrates the grain boundaries. According to the Ge-Cu phase diagram [16], the Gemco alloy is at a completely liquid state at the brazing temperature, and this allows the formation of a thick diffusion layer. Only the diffusion layer can be detected from the morphological analysis, and it clearly exceeds the expected filler metal layer thickness (about $180 \mu \mathrm{m}$ ). According to Figure 5, the diffusion distance in Glidcop/Mo joints obtained using three Gemco braze foils at $980{ }^{\circ} \mathrm{C}$ for $5 \mathrm{~min}$ and for $30 \mathrm{~min}$ is about $250 \mu \mathrm{m}$ and $350 \mu \mathrm{m}$, respectively. As in the case of silver-based brazes, the rate of diffusion of Gemco along the grain boundaries of Glidcop is higher than its rate of diffusion through the grains; as a consequence, there is a preferential diffusion or migration of Gemco along the grain boundaries and a successive formation of voids at the grain boundaries. Conversely, the diffusion rate of the elements contained in the brazing alloys along the grain boundaries is significant in Glidcop, and this allows a rapid migration of the elements inside the materials and a depletion of the joining area.

It has been reported that fine grained Glidcop, which have several grain boundaries, permits a rapid diffusion of the constituents of the braze alloy, particularly Ag, along the grain boundaries [7]. Moreover, this excessive diffusion of elements along the grain boundaries of Glidcop causes the formation of small voids near the braze area. Therefore, in order to limit the diffusion phenomena of $\mathrm{Ge}$ and $\mathrm{Cu}$, the dwelling time was reduced to $1 \mathrm{~min}$; as a consequence, the joining process was carried out at $980{ }^{\circ} \mathrm{C}$, for only $1 \mathrm{~min}$, using three braze layers and applying $0.02 \mathrm{MPa}$. The morphological analysis (not reported here) of the cross section of the Mo/Glidcop joints manufactured according to the 
aforementioned parameters does not differ significantly from that observed for the 5 min dwelling time for the brazing process, as seen in Figure 4. Consequently, to overcome the braze diffusion along the Glidcop grain boundaries, the Glidcop surface was coated with pure $\mathrm{Cu}$ prior to the brazing process.

Copper and nickel coatings are well known barrier layers to the diffusion of metallic elements into Glidcop; the minimum required coating thickness for a brazing treatment is usually a function of the brazing temperature and the brazing time.

Furthermore, the adherence of the coating to the substrate plays an important role. A Watts bath or nickel sulphamate bath are generally used for the nickel plating, and the grain size and orientation of the plated layers can influence the barrier function of the plating. A cyanide bath or an acid copper sulfate bath are currently used for copper plating [10,17].

Instead of these traditional techniques, we performed the Cu plating of Glidcop by means of RF-sputtering. The process has a fast deposition rate, and the thickness of the coating can easily be controlled and tailored on the basis of the brazing parameters.

This coating process is a complete dry and environmental friendly technique; it is a good process to obtain highly reproducible surface quality, without employing environmentally harmful and toxic substances, thus meeting the Registration, Evaluation, Authorisation and Restriction of Chemicals (EU REACh) regulations [18]. Preliminary experiments were carried out with a $1 \mu \mathrm{m} \mathrm{Cu}$ coating sputtered onto Glidcop; the metallographic examination of the joined Glidcop/Gemco/Mo interface did not show any decohesion at the $\mathrm{Cu}$ sputtered/Glidcop interface, and defect-free Gemco/substrate interfaces were observed, as seen in Figure 6. On the other hand, the specimen still exhibited strong intergranular penetration of the braze along the Glidcop grain boundaries (about $200 \mu \mathrm{m}$ through the thickness). An EDS analysis at the grain boundaries in Glidcop, at about $150 \mu \mathrm{m}$ from the Gemco/Glidcop interface, seen in Figure 6B, showed the presence of Ge-enriched grain boundary regions in the Glidcop. As a conclusion, the $1 \mu \mathrm{m} \mathrm{Cu}$ sputtered coating was considered as not being effective against the diffusion of Gemco in Glidcop.
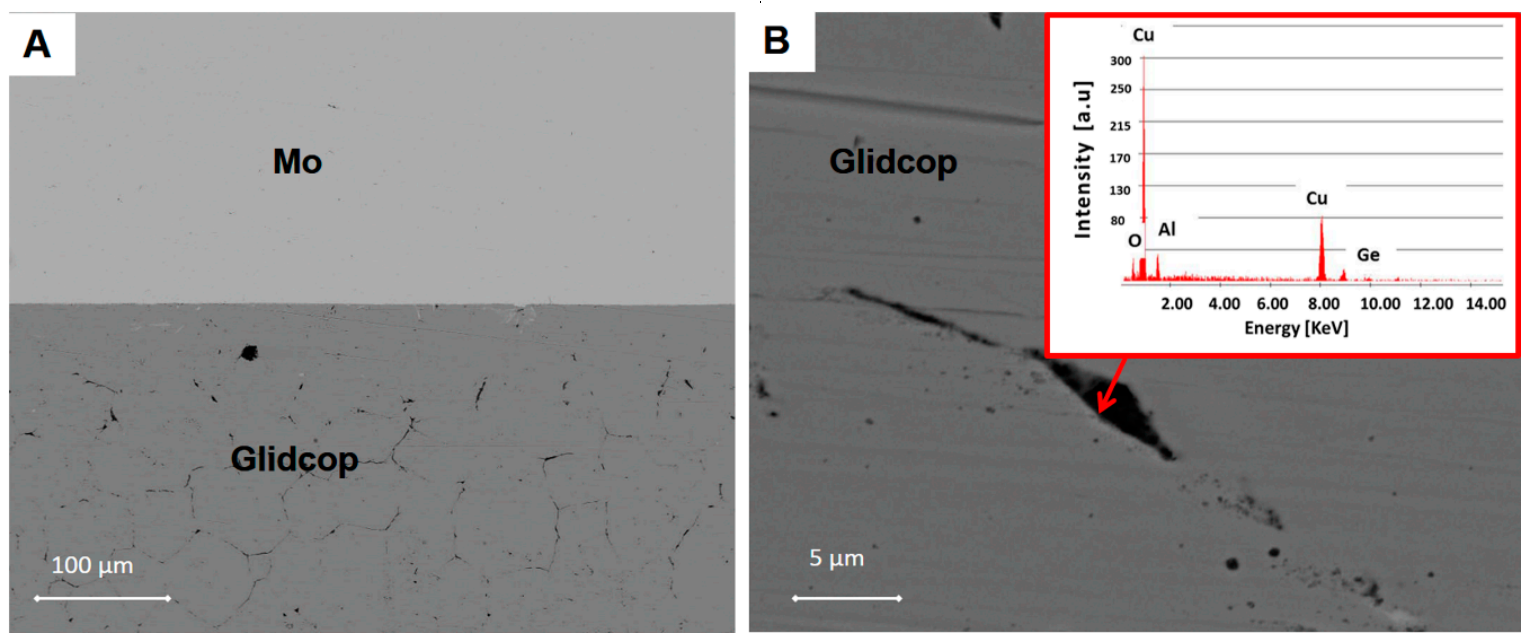

Figure 6. Scanning electron micrographs of (A) the cross-section of 1- $\mu \mathrm{m}$ thick $\mathrm{Cu}$ - plated Glidcop/Mo joint; (B) magnification of a grain boundary in the Glidcop and relative EDS analysis (inset) at about 150 microns from Glidcop/Gemco interface.

To corroborate this statement, the distribution of the considered elements, obtained from an EDS analysis across the joint region, is shown in Figure 7. The diagram is scaled with respect to the distribution of the elements at the Glidcop/Mo interface. The main braze constituents diffused significantly in the Glidcop up to $600 \mu \mathrm{m}$ from the interface. On the other hand, Ge-Mo intermetallic phases were able to form at the interface between the Gemco and Mo, according to the phase diagram. Moreover, the EDS analysis detected Ge (up to $4 \%$ ). 


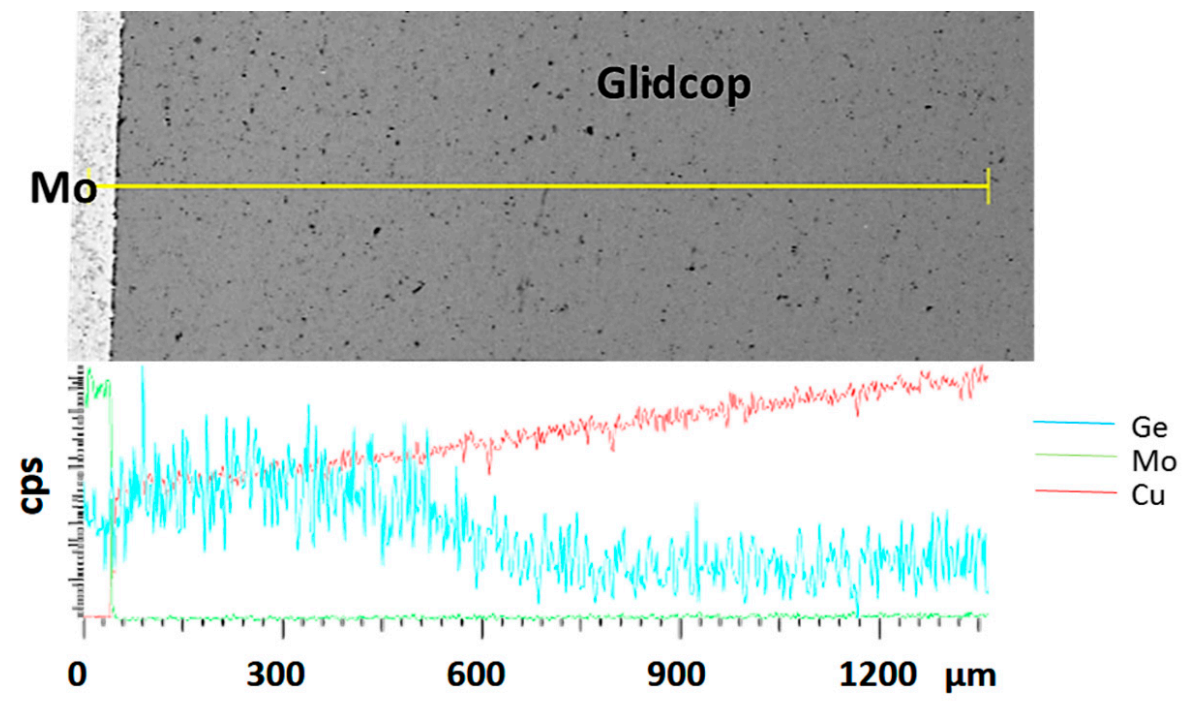

Figure 7. Element distribution (Ge, $\mathrm{Cu}$ and $\mathrm{Mo}$ ) across the 1- $\mu \mathrm{m}$ thick $\mathrm{Cu}$ plated Glidcop/braze/Mo joint.

The same analysis was carried out on the joints obtained with a thicker $(18 \mu \mathrm{m}) \mathrm{Cu}$ sputtered layer on Glidcop; this value was chosen according to the values reported in literature for electrochemical plating (minimum 15-20 micron). Figure 8 shows the cross-section of a 18- $\mu \mathrm{m}$ thick $\mathrm{Cu}$ plated Glidcop/Gemco/Mo joint; no voids are detectable at the braze/adherend interface or along the Glidcop grain boundaries, thus demonstrating that the thicker copper coating successfully limited the diffusion of elements from the braze along the grain boundaries of Glidcop and allowed the formation of a defect-free brazed joint. The EDS element maps reported in Figure 8B-D demonstrate that the Ge was confined to the braze alloy (about $180 \mu \mathrm{m}$ thick) and did not diffuse into the Glidcop alloy.

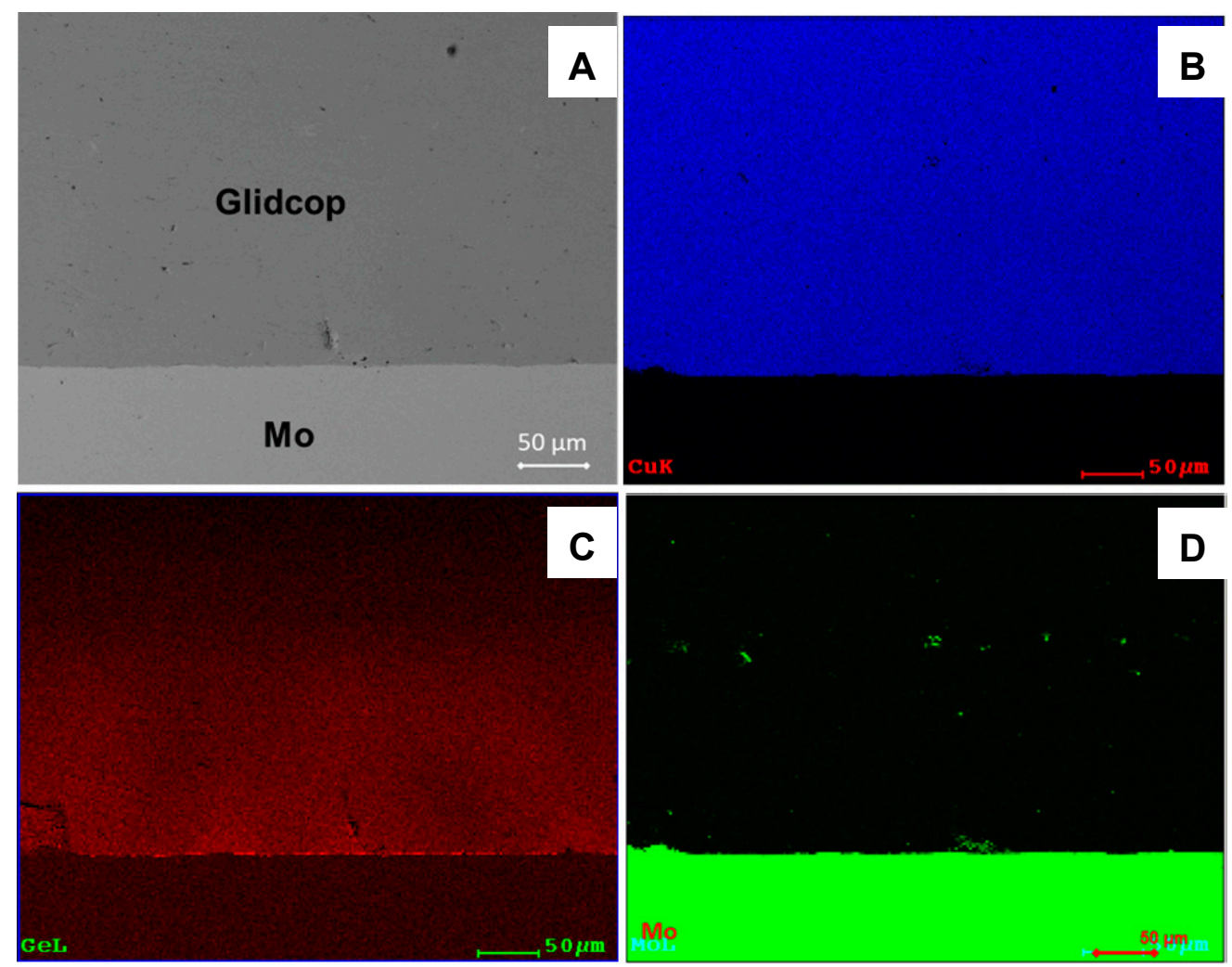

Figure 8. (A)SEM cross-section of an 18- $\mu \mathrm{m}$ thick Cu plated Glidcop/Mo joint; (B) Cu EDS mapping; (C) Ge EDS mapping; (D) Mo EDS mapping. 
In short, the excessive reduction of the filler in the Glidcop, and the consequent formation of detrimental voids in the alloy, can be avoided by depositing a $\mathrm{Cu}$ diffusion barrier coating by means of RF-sputtering. Moreover, unlike the commonly adopted electroplating process, this is a simple process that does not require chemicals or lead to blister formation at the plating/substrate interface.

In conclusion, the optimal brazed specimens were manufactured at $980{ }^{\circ} \mathrm{C}$ for $1 \mathrm{~min}$, under flowing Ar by using three Gemco foils as brazing material, after having $\mathrm{Cu}$-plated the Glidcop surface by an $18 \mu \mathrm{m} C u$ layer by RF-sputtering.

As a consequence, the optimized joints are four components sandwiched, made of Glidcop, thin $\mathrm{Cu}$ layer, braze foils, and Mo block.

\section{Mechanical Tests}

Some joints, manufactured using the optimized process were mechanically tested in a single-lap test to determine the apparent shear strength. The fracture did not occur in the joined area, but all the tested samples detached from the fixture, seen Figure 1B; the glue failed for stresses of up to $42 \mathrm{MPa}$, and no fracturing occurred in the joined samples. Unlike what was observed where a $\mathrm{CuZr}$ alloy was joined to Mo using the same braze [4], no plastic deformation occurred in Glidcop, but, since no failure of the joint was observed, this test configuration could not be used to test the apparent shear strength of these joints.

As a consequence, other brazed specimens were manufactured, according to the ASTM B898-11 standard, seen in Figure 1A, and an average value of $68.5 \pm 18.0 \mathrm{MPa}$ was measured. The fracture surface analysis shows that cracks occurred preferentially in the braze and/or at the braze/Glidcop interface, but not at the braze/Mo interface. Figure 9 shows the typical fracture surfaces for a Mo/Glidcop joined sample: the presence of the brazing alloy is evident on both sides.

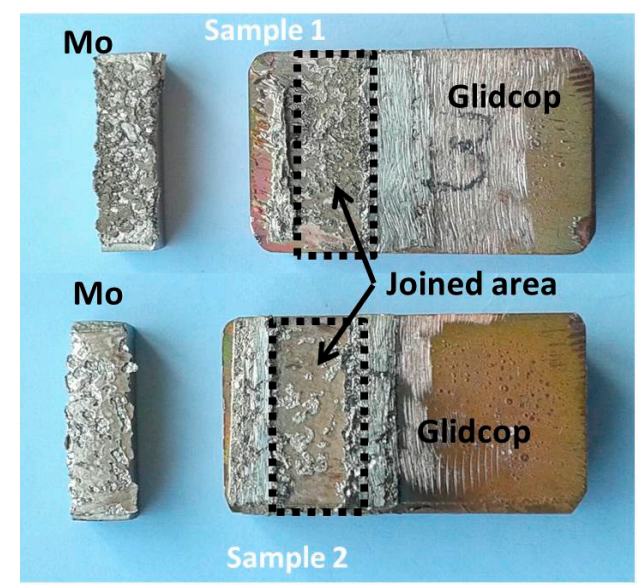

Figure 9. Fracture surface of Mo/Glidcop brazed samples after apparent shear test according to ASTM B898-11.

The fracture mechanism involves coalescence of the microvoids, seen in Figure 10, as in a typical ductile failure. Furthermore, the EDS analysis performed on all the areas marked in Figure 10 only revealed the presence of $\mathrm{Cu}$ and Ge contained in the brazing alloy on both of the fracture surfaces; the relative amount of these elements points out that the failure occurred mainly within the braze, thus indicating a lower joint strength between the braze and the Glidcop than the shear strength of the dispersion-strengthened alloy itself. The cohesive behavior of the joined samples after testing demonstrates the good adhesion at the Mo/braze and Glidcop/braze interface. 


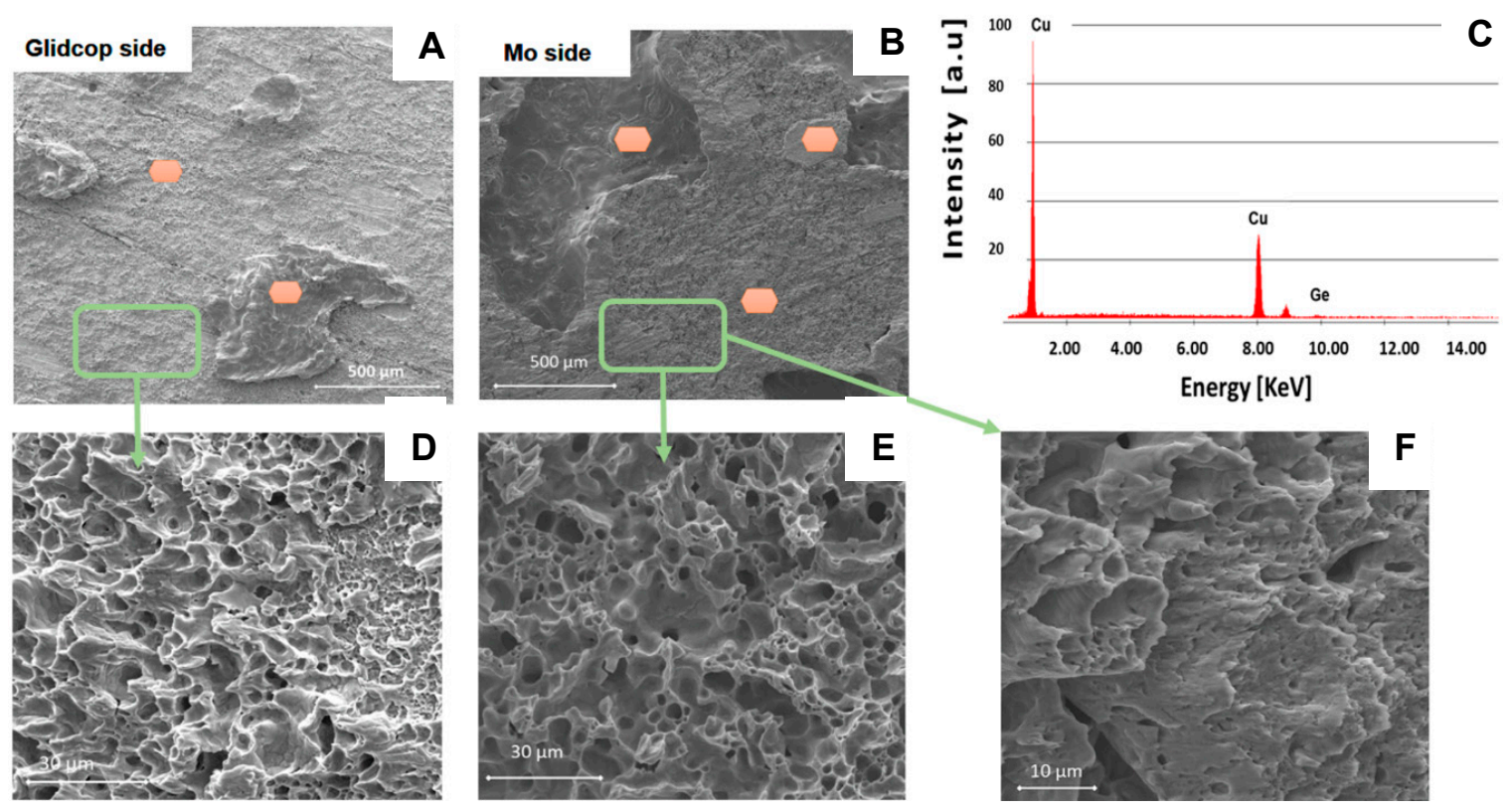

Figure 10. SEM and EDS analysis on Glidcop and Mo fracture surface apparent shear test according to ASTM B898-11; on both surfaces only $\mathrm{Cu}$ and Ge have been detected, thus indicating that cracks propagate within the braze and in some areas close to or in Glidcop; the EDS spectrum refers to measurements done in all the orange areas. (A) fracture surface of Glidcop side; (B) fracture surface of Mo side; (C) EDS analysis on orange areas of fracture surfaces shown in (A,B); (D) magnification of fracture surface area on Glidcop side; (E) magnification of fracture surface area on Mo side; (F) higher magnification of area shown in (E).

Hardness tests were carried out in order to investigate the influence of the brazing process on the Glidcop properties; the hardness values of the Glidcop, before and after the brazing process, were $70 \pm 2$ Hardness Rockwell B (HRB) and $74 \pm 1$ HRB, respectively. These data show that the brazing process does not result in a significant change in the mechanical properties of the Glidcop, relative to its hardness.

\section{Conclusions}

The joining of Glidcop AL-25 and Mo has been investigated in detail. A brazing process that involved a commercial Cu-based alloy (Ag free) was studied; it led to microstructurally continuous joints with good shear strength.

In light of the results of this investigation, the joining parameters were then optimized and $\mathrm{Cu}$ plating, by means of sputtering, was used to prevent diffusion of the brazing elements across the joint interface. Unlike the commonly adopted electroplating process, this is a simple process that does not require chemicals or lead to blister formation at the plating/substrate interface.

The optimization of the joining process was based on the number of braze foils and on the study of diffusion of the brazing elements in Glidcop. The sputtering of a copper diffusion barrier on Glidcop, to prevent diffusion of the braze, was effective in reducing but not in completely eliminating the formation of voids and cracks, as a result of the preferential migration of braze along the Glidcop grain boundaries.

The optimal brazed specimens were obtained at $980{ }^{\circ} \mathrm{C}, 1 \mathrm{~min}$, under flowing Ar, using 3 Gemco foils as brazing material, after having $\mathrm{Cu}$-plated the Glidcop surface by a $18 \mu \mathrm{m} \mathrm{Cu}$ layer by RF-sputtering. The apparent shear strength (adapted from ASTM B898-11) on the optimized joined samples was about $68 \mathrm{MPa}$. 
Author Contributions: V.C. performed experimental analysis and interpretation of data and contributed in writing original draft; S.P. contributed in experimental activity; M.F. contributed in supervision and validation of the activity; M.T. contributed in revision of the draft and analysis of data; G.A.I. and S.S. contributed to the conception of the work; M.S. contributed equally as first author.

Funding: This research received no external funding.

Conflicts of Interest: The authors declare no conflict of interest.

\section{References}

1. Aghamiri, S.M.S.; Oono, N.; Ukai, S.; Kasada, R.; Noto, H.; Hishinuma, Y.; Murogac, T. Microstructure and mechanical properties of mechanically alloyed ODS copper alloy for fusion material application. Nucl. Mater. Energy 2018, 15, 17-22. [CrossRef]

2. Bertarelli, A.; Aberle, O.; Assmann, R.; Chiaveri, E.; Kurtyka, T.; Mayer, M.; Perret, R.; Sievers, P. The mechanical design for the LHC collimators. In Proceedings of the EPAC, Lucern, Switzerland, 17 August 2004; EPAC-MOPLT008. Available online: http:/ / accelconf.web.cern.ch/accelconf/e04/papers/moplt008.pdf (accessed on 13 July 2018).

3. Bertarelli, A.; Dallocchio, A.; Garlasché, M.; Gentini, L.; Gradassi, P.; Guinchard, M.; Redaelli, S.; Rossi, A.; Sacristan de Frutos, O.; Quaranta, E. Novel materials for collimators at lhc and its upgrades. In Proceedings of the 54th ICFA Advanced Beam Dynamics Workshop on High-Intensity, High Brightness and High Power Hadron Beams, HB2014, East Lansing, MI, USA, 10-14 November 2014. Available online: http:/ / accelconf.web. cern.ch/AccelConf/HB2014/papers/tho4ab03.pdf (accessed on 13 July 2018).

4. Salvo, M.; Casalegno, V.; Rizzo, S.; Ferraris, M.; Izquierdo, G.; Heikkinen, S.; Sgobba, S.; Taborelli, M. Brazing of Mo to a CuZr alloy for the production of bimetallic raw materials for the CLIC accelerating structures. J. Mater. Process. Technol. 2010, 210, 791-798. [CrossRef]

5. Ljvak, R.J.; Frost, H.M.; Zocco, T.G.; Kennedy, J.C.; Hobbs, L.W. Promising copper alloys for high heat load applications in neutron environments. J. Nucl. Mater. 1986, 141-143, 160-162. [CrossRef]

6. Braham, C.; Coppola, R.; Nardi, C.; Valli, M. High temperature stresses in brazed Glidcop/W model structures of interest for ITER divertor technology. Fusion Eng. Des. 2005, 75-79, 391-394. [CrossRef]

7. Yadav, D.P.; Kaul, R.; Ram Sankar, P.; Kak, A.; Ganesh, P.; Shiroman, R.; Singh, R.; Singh, A.P.; Tiwari, P.; Abhinandan, L.; et al. A study on brazing of Glidcop ${ }^{\circledR}$ to OFE Cu for application in Photon Absorbers of Indus-2. J. Phys. Conf. Ser. 2012, 390, 012019. [CrossRef]

8. Nishi, H.; Muto, Y.; Sato, K. Solid-state diffusion bonding of alumina dispersion-strengthened copper to 316 stainless steel. J. Nucl. Mater. 1994, 212-215, 1585-1589. [CrossRef]

9. Nishi, H.; Kikuchi, K. Influence of brazing conditions on the strength of brazed joints of alumina dispersion-strengthened copper to 316 stainless steel. J. Nucl. Mater. 1998, 258-263, 281-288. [CrossRef]

10. Chen, S.; Bao, T.; Chin, B.A. Braze joints of dispersion strengthened copper. J. Nucl. Mater. 1996, 233-237, 902-905. [CrossRef]

11. Chen, S.; Liu, J.Y.; Chin, B.A. Effect of alumina strengthening particles on brazed joints of GlidCop Al-15 copper alloy. J. Nucl. Mater. 1994, 212-215 Pt B, 1600-1603. [CrossRef]

12. ASTM D905-08 (2013) Standard Test Method for Strength Properties of Adhesive Bonds in Shear by Compression Loading; ASTM International: West Conshohocken, PA, USA, 2013.

13. ASTM B898-11 (Reapproved 2016) Standard Specification for Reactive and Refractory Metal Clad Plate; ASTM International: West Conshohocken, PA, USA, 2016.

14. Tomsia, A.P.; Saiz, E.; López-Esteban, S.; Benhassine, M.; De Coninck, J.; Rauch, N.; Rühle, M. Wetting of metals and glasses on Mo. Int. J. Mater. Res. 2007, 98, 1238-1243. [CrossRef]

15. Toter, W.; Sharma, S. Analysis of Gold-Copper Braze Joints in Glidcop ${ }^{\circledR}$ for UHV Components at the Advanced Photon Source. 2004. Available online: http:/ / citeseerx.ist.psu.edu/viewdoc/summary?doi=10.1. 1.693.9571 (accessed on 13 July 2018).

16. Wang, J.S.; Leinenbach, C.; Jacot, A. Thermodynamic assessment of the Cu-Ge binary system. J. Alloys Compd. 2010, 504, 159-165. [CrossRef] 
17. Sgobba, S. Materials of High Vacuum Technology: An Overview. In CAS-CERN Accelerator School and ALBA Synchrotron Light Facility: Course on Vacuum in Accelerators; CERN: Geneva, Switzerland, 2006; pp. 117-144. Available online: https:/ /cds.cern.ch/record/983744/files/p117.pdf (accessed on 13 July 2018).

18. Regulation (EC) No. 1907/2006 of the European Parliament and of The Council of 18 December 2006 Concerning the Registration, Evaluation, Authorisation and Restriction of Chemicals (REACH), Establishing a European Chemicals Agency; Amending Directive 1999/4: REACH; KFT Chemieservice GmbH: Griesheim, Germany, 2013.

(c)

(C) 2018 by the authors. Licensee MDPI, Basel, Switzerland. This article is an open access article distributed under the terms and conditions of the Creative Commons Attribution (CC BY) license (http:/ / creativecommons.org/licenses/by/4.0/). 